\title{
Tissue microarrays and their use for preparation of reference slides for educational purposes in histology and histopathology
}

\author{
Salah Deeb, Mohamed Badii, Mahmoud El-Begawey, Khalid Ali and Emad Mahdi
}

Department of Pathology, Faculty of Veterinary Medicine, Beni Suef Veterinary Tissue Bank Egypt (HEEPF)

\begin{abstract}
SUMMAY
Use of Tissue array was first applied in 1998, and has received a significant amount of attention from the research community ever since. In this technique, a large number (up to 1000) of cylindrical tissue core extracted from "donor" paraffin block are deposited into "recipient" block. The aim was modification of the technique of tissue array for manual preparation of the recipient block and production of slides of educational interest in histology and histopathology. The area of interest was localized with the help of stained section, the area was punctured, and the cylindrical core of tissue removed was then introduced into another (recipient) paraffin block. Puncture method was suitable only for parenchymatous organs (liver, kidney, heart, spleen, etc.) but longitudinal sections were required for tubular (gastrointestinal tract, urinary tract, genital tract) and hollow organs (gallbladder, urinary bladder) and brain. The method described is of importance in procurement of materials for preparation of slides for educational purposes and in overcoming the shortage of these materials especially in the field of pathology
\end{abstract}

[Afr J Health Sci. 2006;13: 66-69]

\section{Introduction}

Histology and histopathology are two basic sciences essential for medical education for underand postgraduates. Presence of facilities in the form of well-identified tissue specimens as reference slides has, indeed, a positive gain on the education process. Enhancement of performance of the education process in the field of histology and histo- pathology can be improved by sustained procurement of original tissue specimens and their availability to each student or researcher. In histopathology, rare cases in tumors may be represented by type, various scoring and grading and in infections by various stages. Specimens are required, moreover, for histochemical reactions, immunohistochemistry, immunofluorescence, and autoradiography for normal tissue and pathological materials. The solution may be provided by application of the technology of tissue microarrays and construction of multispecimen tissue blocks.

The technology of tissue microarrays was first introduced by Kononen et al. [1]. This technology has received a significant amount of attention from the research point of view. In this technology, a large number of cylindrical core tissue samples is first extracted from original tissue specimens (donor paraffin blocks). The cylindrical core tissue are then deposited into recipient paraffin blocks. The number of specimens per array depends on the size of punches and the desired array density. Using $0.6 \mathrm{~mm}$ punches, one can construct tissue array with 500 specimens or more per block using regular tissue arrayer. Using $2.0 \mathrm{~mm}$ punches allows construction of tissue arrays with about 50100 specimens. Final microarray paraffin block is cut to produce several hundreds of tissue sections. Hidalgo et al. described a simplified manual method for construction of small format tissue array [2]. Petrosyan and Press describe a multichambered ("honey comb") tissue mold that simplifies the technique of embedding of many tissue samples in a single paraffinized specimen block [3]. Trials for construction of tissue microarrays manually revealed some difficulties in manufacturing the prearranged specimen distribution during processing. Moreover, tissue microarrays were not convenient for tubular or hollow organs such as the gastrointestinal tract, or barin for example. An alternative technique in the latter cases was the construction of multispecimen blocks. Wide ranges of slides are commercially available including slides that comprise a wide range of normal human and animal tissue and tumors. These slides are relatively expensive and it is not economical to be distributed to students on a large scale. It is quite rational to encourage different departments of histology and pathology to produce their own educational material. It is to be emphasized that most of the work devoted to tissue microarrays or multispecimen block construction is traditional pathology work that can be done in any laboratory. 


\section{Material and Methods}

Normal tissue was obtained from sacrificed rats and slaughterhouse material, while pathological tissue samples were provided through archived formalin-fixed paraffin-embedded material from "Veterinary Tissue Bank Egypt" (Department of Pathology, Beni-Suef, Egypt). This material, embedded in paraffin blocks, resembled the "donor-blocks". Selected pathological material was diagnosed and areas of interest were identified.

\section{Construction of tissue microarrays}

A paraffin block containing a supporting mold consisting of formalin-fixed paraffin embedded rectangular slice $(2.0 \mathrm{~mm}$ thick, $2.0 \mathrm{~cm}$ wide, 3.0 $\mathrm{cm}$ long) was used to receive the cylindrical core tissue from donor blocks. In this " recipient block" small punches of $2.0 \mathrm{~mm}$ in diameter were manually cut at room temperature. Cutting instrument was simple home-made stainless steel driller similar to a trocar and cannula.

\section{Fig 1: Construction of an array slide}

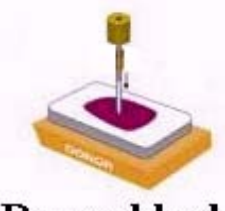

\section{Donar block}

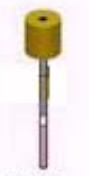

To recipient block

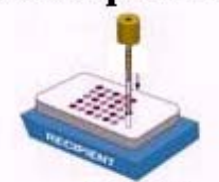

Array

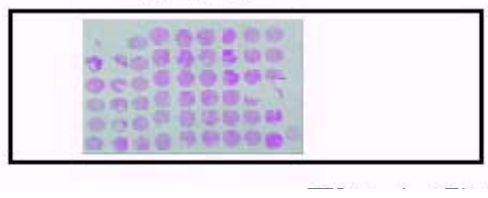

The same driller was used to obtain tissue cylinders from selected paraffin-embedded samples (donor blocks). These tissue cylinders were introduced into pre-made holes in the recipient block (Fig. 1). Once the array was completed, the block was incubated in an oven at $70 \mathrm{C}$ with the surface upside down for $30 \mathrm{~m}$ to help blending of the wax from tissue cylinders with that of the recipient block. Presence of supporting mold (in the form of embedded rectangular liver slice) maintain the specimen distribution and preserves the upright position and leveling of introduced tissue cylinders. Constructed tissue array blocks can be sectioned using rotary microtome. We could get regular nondistorted sections in which the arranged samples stick firmly to the slides without need of use of tape transferring technique. Sections can be routinely stained with hematoxylin and eosin or any other stain (immunohistochemistry, immunofluorescence, in-situ hybridization).
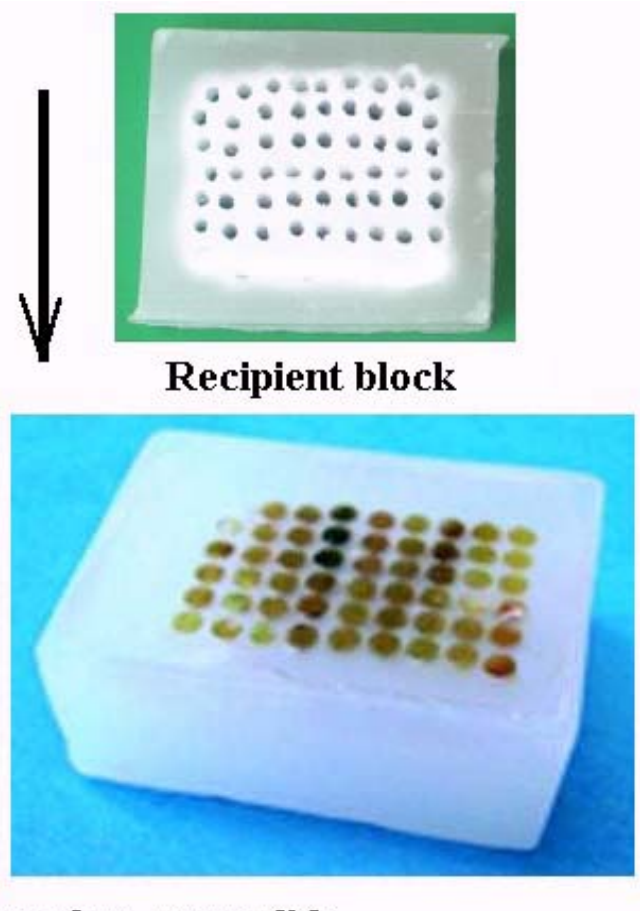

Construction of multispecimen blocks Organs selected must be trimmed in a suitable manner that depends on their size, anatomical and histological structure (Fig. 2). The major limiting factor in preparation of reference slides was the orientation of tissue specimens within the block. Each organ has its peculiarity; large organs can be prepared as arrays in parts. Trimmed tissue samples were fixed in $10 \%$ neutral formalin solution for at least 48 hours and processed for impregnation in paraffin wax by conventional method. Samples were removed from molten wax, and transferred to a host paraffin wax box containing a basal layer of paraffin wax, only $1.0 \mathrm{~mm}$ thick, and were arranged regularly. Once the array was completed, a small amount of hot molten paraffin wax was poured over the array surface slowly using eye-dropper until the host-box is filled. To blend together the paraffin wax from the host box and tissue samples, the arrays was incubated in an oven at $65 \mathrm{C}$ for one hour. After incubation, the block was cooled down 
and sectioned at 5 um thickness using large specimen sliding microtome. Arrayed sections

\section{Fig 2: Convenient cutting directions of some organs}
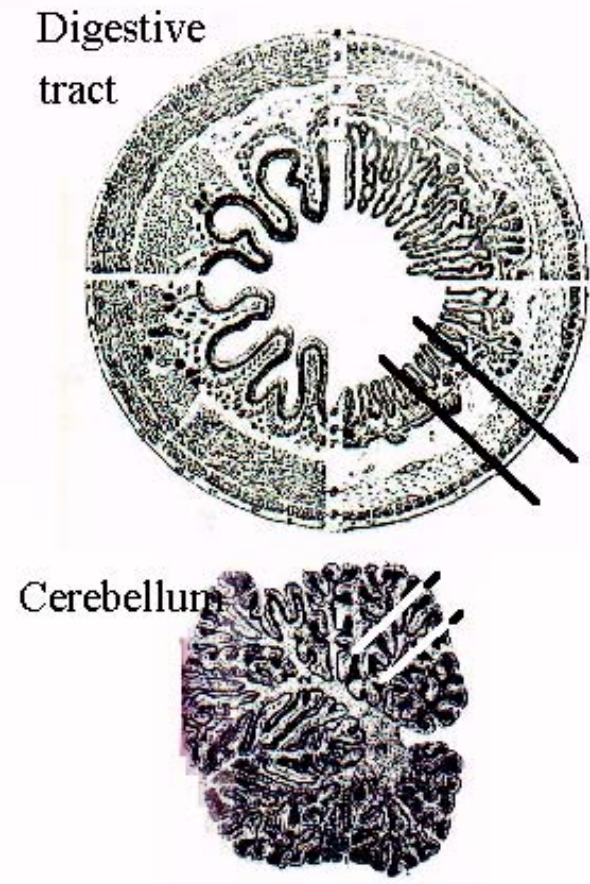

\section{Results}

In an array, cylinders of tissue core $2.0 \mathrm{~mm}$ in diameter were convenient to get suitable area (3.0 $\mathrm{mm}^{2}$ ) from parenchymatous organs such as the liver, kidney, etc. Table I shows organs and tissue suitable to be demonstrated as tissue microarrays. For construction of multispecimen blocks, trimming was essential to minimize the area and volume of the tissue to be impregnated in paraffin.

Table 2 shows the most suitable cutting level of tubular and hollow organs and structures of interest to be demonstrated. Modifications are required to cut in organs such as brain, heart, gallbladder and urinary bladder. Arrangement of tissue specimens in one paraffin block must be rational and empty spaces must be minimized as much as possible. For educational purposes, it is better to put organs related to one and the same system together. A few number of organs must be treated separately, either because they are large and from large animals or man, e.g., the ovary, or because they are too complicated, e.g., the brain. Examples of cut organs are shown schematically in Fig. 2.

\section{Discussion}

Tissue microarrays are useful for a variety of applications including morphometrical characterization of tissue in tumors and molecular analysis such as immunohistochemistry, fluorescence in-situ hybridization, and mRNA insitu hybridization, as well as in drug discovery, and were then ready for staining.
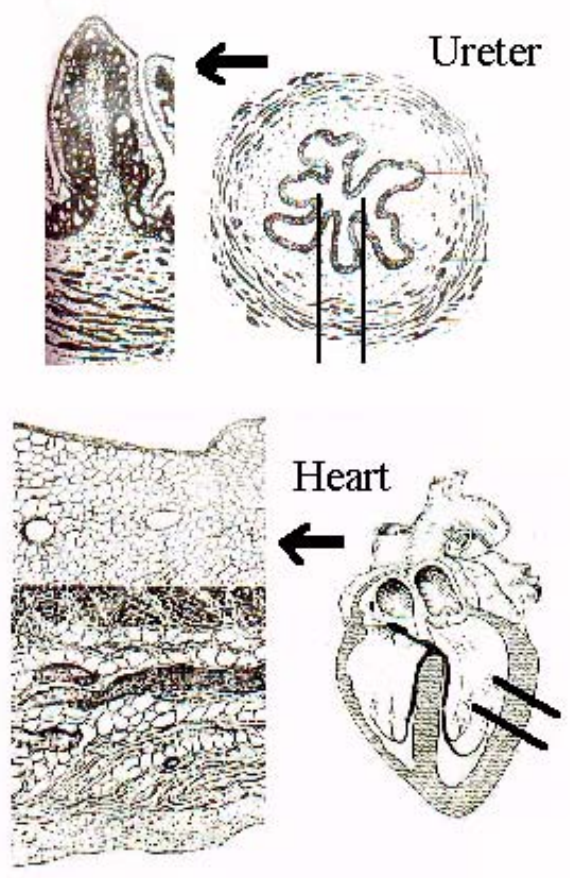

monitoring of hygiene and environment as reported by Dan et al.[4] and Packeisen et al.[5]. In the present work, we described the construction of tissue microarrays and manufacturing of multispecimen blocks to get several hundreds of slides that can be distributed on large scale for educational purposes.

Modification of manual construction of tissue micoarays using a supporting mould in the form of liver slice was proved to be effective. It has the advantage of maintaining the prearrangement of array distribution, and there was no need for use of tape transferring technique. Preparation of glass slides for educational purposes by this method is easy, less time-consuming, and spare reagents and labor. Once constructed, they can be distributed on large scale. Interesting lesions can be harvested from archival pre-existing paraffin blocks. The consumption of "donor blocks" $(2.0 \mathrm{~mm})$ was low that make rare tissue more available. Tissue arrays construction by this method did not require special tools. Punched area $(2.0 \mathrm{~mm}$ in diameter) involves sufficient tissue elements for morphological demonstration of important structures/lesions. Depending on the size of punches used (0.6 to $2.0 \mathrm{~mm}$ in diameter), from 60-300 tissue can be arranged on one slide (Yale Mouse Research Pathology ) [6]. In cases in which construction of tissue microarrays by puncture is not convenient, the use of multispecimen block method is a suitable alternative; it is cost-effective 
and conserves time and reagents. Slides produced by this method are efficient as educational material for histology and histopathology. Trimming and orientation are very important parameters to get representative slides.

Table 1. Tissue and organs suitable to be processed either by puncture method or multispecimen method

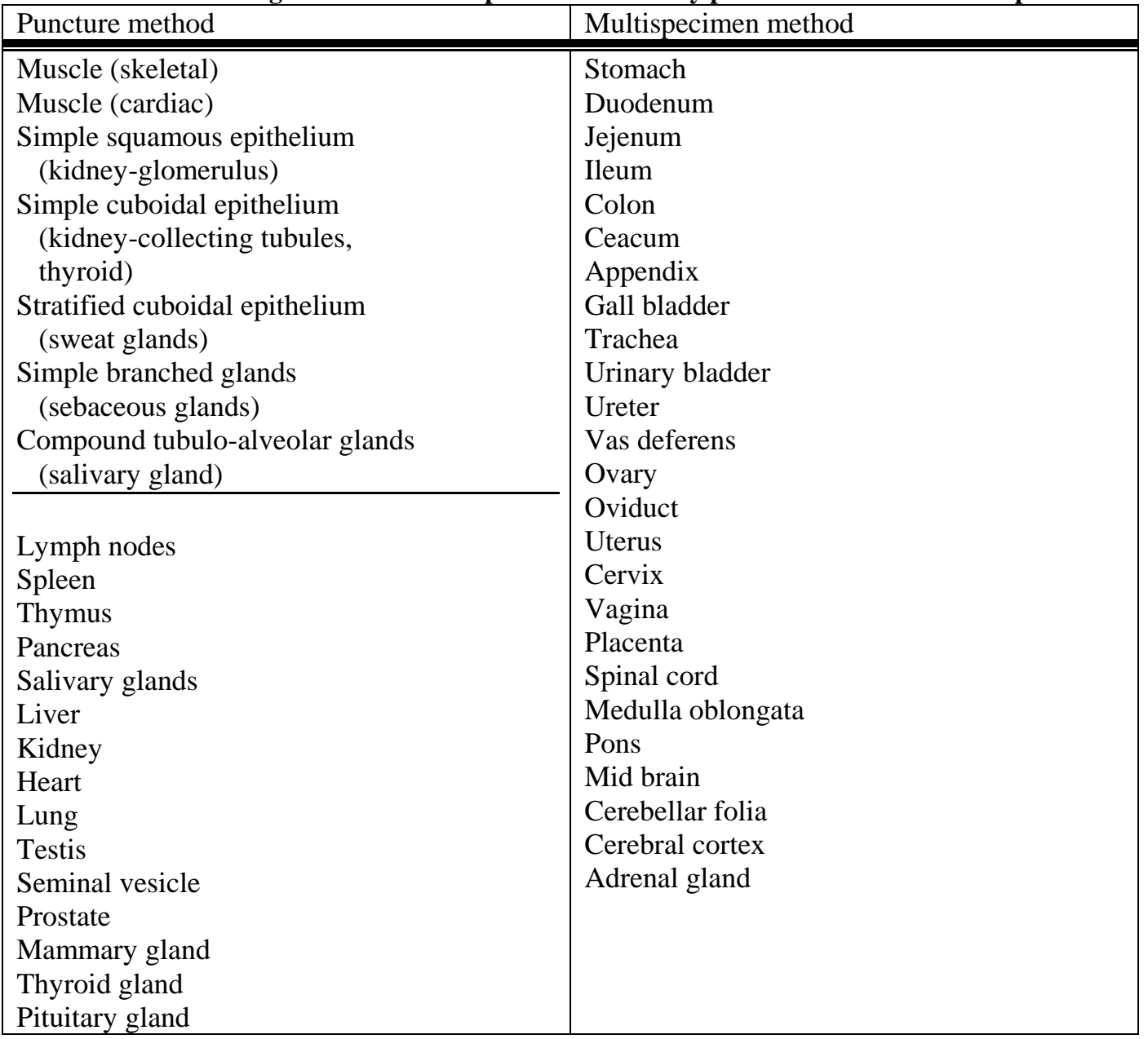

\section{Conclusion}

The method described is of imporance in procurement of materials for preperation of slides for educational purposes and in overcoming of the shortage of these materials especially in the field of pathology. Few slides can cover the whole course; this much more economical and rational.

\section{References}

1. Kononen J, Bubendorf L, Kallioniemi A, Barlund M, Schraml P, Leighton S, Torhorst J, Mihatsch MJ, Sauter G and Kallioniemi OP. Tissue microarrays for highthroughput molecular profiling of tumor specimens. Nature Medicine. 1998; 4:844-847.

2. Hidalgo A, Pina P, Guerrero G, Lazos M and Salcedo M . A simple method for construction
Clinical Pathology. 2003; 56:144-146

3. Petrosyan K and Press MF. Multispecimen tissue blocks in pathology: An improved technique of preparation. Laboratory Investigation . 1997; 77:541-542

4. Dan HL, Zhang YL, Zhang Y, Wang YD, Lai ZS, Yang Y, Cui HH, Jian YT, Geng J, Ding YQ, Guo CH, and Zhou DY. A novel method for preparation of tissue microarray. World Journal of Gastroenterology. 2004; 15:579582

5. Packeisen J, Korsching E, Herbst H, Boecker $\mathrm{W}$ and Buerger $\mathrm{H}$. Tissue microarray technology. Molecular Pathology. 2004; 56:198-204

6. Yale Mouse Research Pathology. Tissue Array Services. 2003. http://mrp.yale.edu/tissue.html. $5^{\text {th }}$ April 2006 